FIFTY YEARS' PROGRESS IN CLOCKS AND WATCHES.-I.

HOROLOGY being one of the oldest aits and $H$ branches of science, it is almost iner." that advances in it should be of a mediocre and modest character, and not of a nature to claim great attention in these days of startling and sensational discovery. But nevertheless during the period we refer to much good work has been done. In chronometers, the secondary compensation error has been discovered and means found to rectify it. In clocks, the same has been done for the barometric error. Moreover, the difficulties connected with the correct working of gravity escapements have been overcome ; so that scarcely a good turret clock is made without one now. Electricity also has been largely applied for driving or controlling clocks, or for controlling chronometers ; and the measurement of minute fractions of a second has been attained by chronographic appliances of extreme accuracy. Articles explanatory of these subjects have appeared in the pages of NATURE ${ }^{1}$ from time to time. In addition there has been a mass of subsidiary improvements which it is impossible to classify, and of which we shall have to describe the leading features in $\dot{a}$ somewhat desultory manner in the succeeding pages.

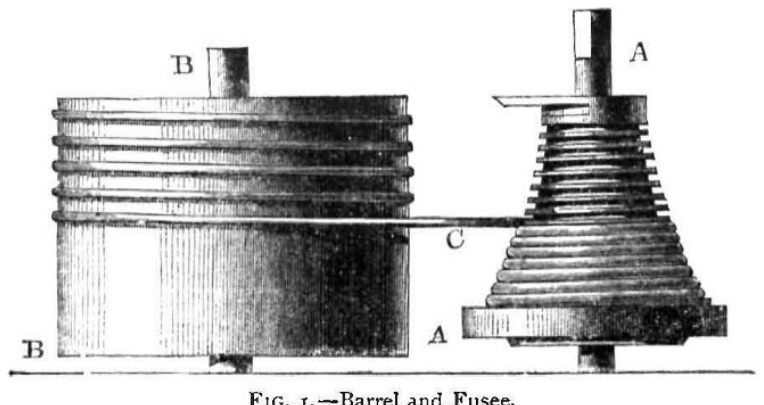

Naturally, the first subject to claim our attention is that important mechanism which enables us to wind up and

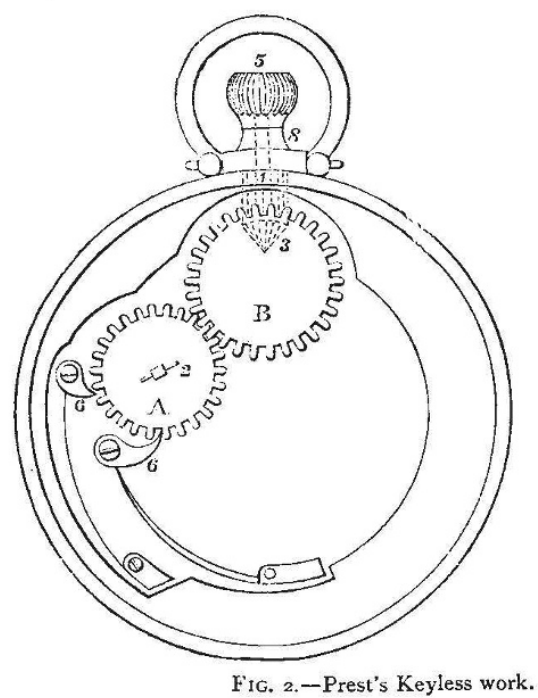

set the hands of our watches without a key. And it is to be remarked that its introduction has led to the almost

${ }^{x}$ See vols. xiv. pp. 529, 554, 573; xv. 9; xx. 345 ; xxiii. 59 ; xxvi. xo7, 369. general abandonment in watches of the fusee (A A, Fig. I), a contrivance of considerable antiquity, a picture of which used to appear in nearly every popular book on mechanics
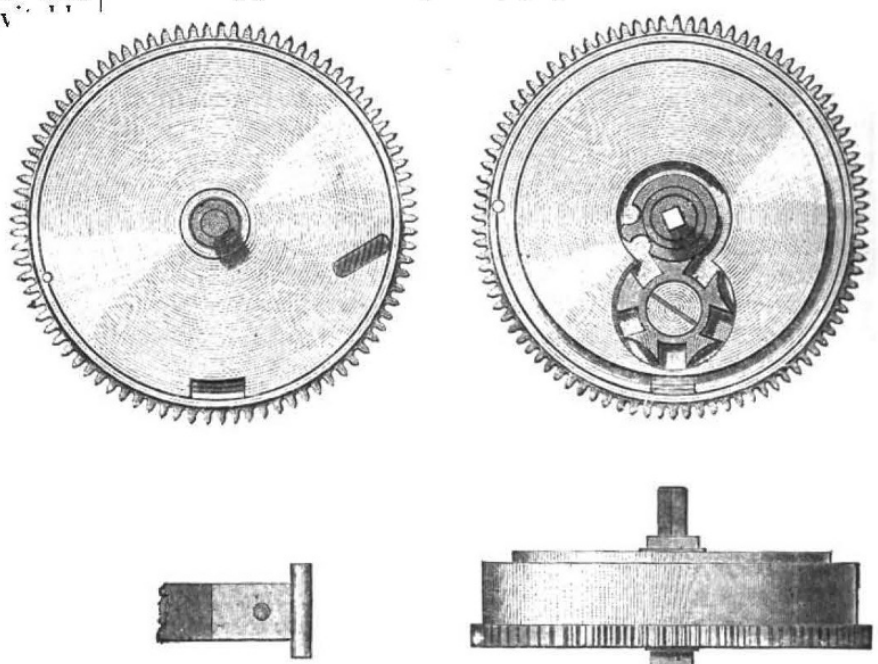

FIG. 3.-Going Barrel and Stop-work.

a few years ago. The discovery of such mechanism was not made all at once; at first it was applied solely for the

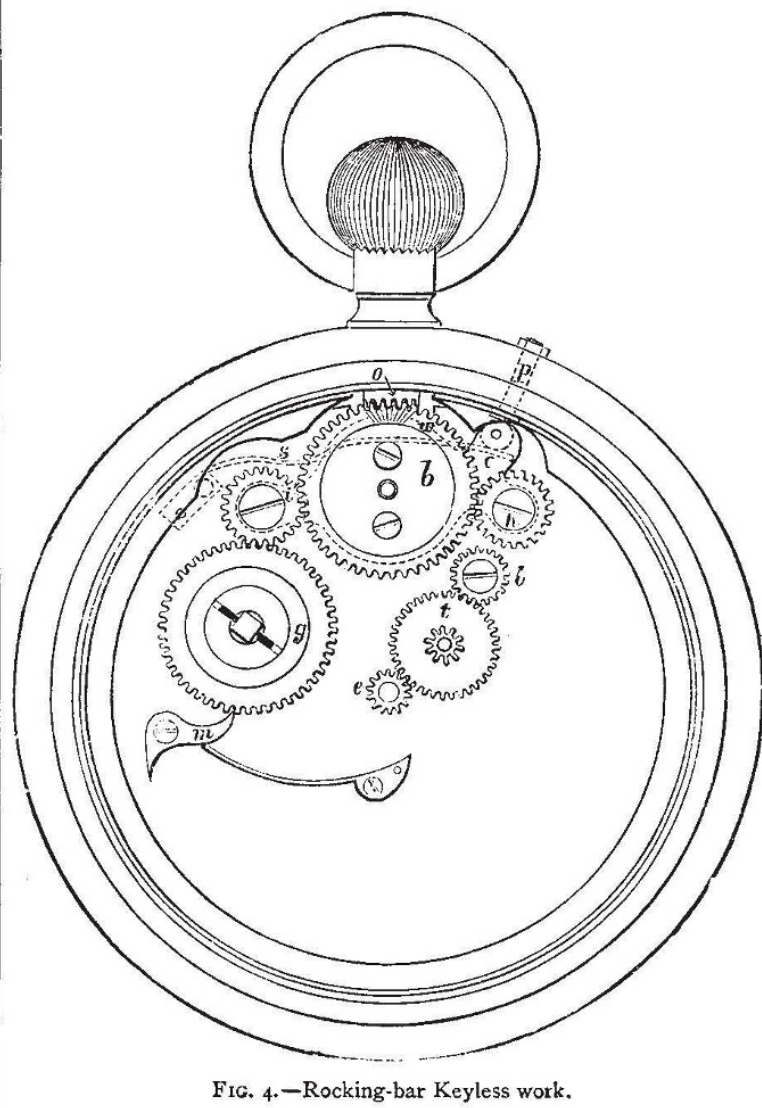

purpose of winding up the watch. The conception of the present form of winding from the pendant is due to Prest 
of Chigwell, and Fig. $2^{1}$ shows his plan. 2 may be considered the same as the square to which the key would be applied in winding, and the wheel $\mathrm{A}$ is fastened to it and is geared to $B$, which in turn engages the pinion 3, which is part of the stalk 4 , passing through the pendant 8 , and terminating in the crown-piece 5 . On turning 5 , A will revolve, winding up the watch in doing so ; the clicks 66 prevent A from returning. It is now clear why the fusee must be dispensed with. With a fusee (whilst the watch is going) the square which you wind travels backwards, and it would naturally turn the crown-piece in doing so ; this"latter, meeting with resistance in the pocket, would obviously stop the watch. Fig. 3 shows the mechanism which takes the place of the fusee. It will be seen that the main wheel is attached to the barrel ; the shaft (squared at its extremities) which passes through the barrel is con- nected with the main-spring; when the shaft is turned the main-spring is wound. The shaft, being held by the intervention of the clicks, cannot return, and the outside of the barrel being urged to follow it by the pulling of the main-spring, impels the main wheel and drives the train. Overwinding is prevented by means of the star wheel and finger-piece shown in the diagram. Every turn of the shaft causes the star to move on one division, but on passing the last division the circle, out of which the finger is cut, meets a convex instead of a concave surface, and further movement is arrested. There is much less difference between the pull of the main-spring when the watch is wound up and nearly down than might be expected. To obtain as much uniformity as possible a long thin main-spring is used, it is tapered, and very few turns of it are brought into service.

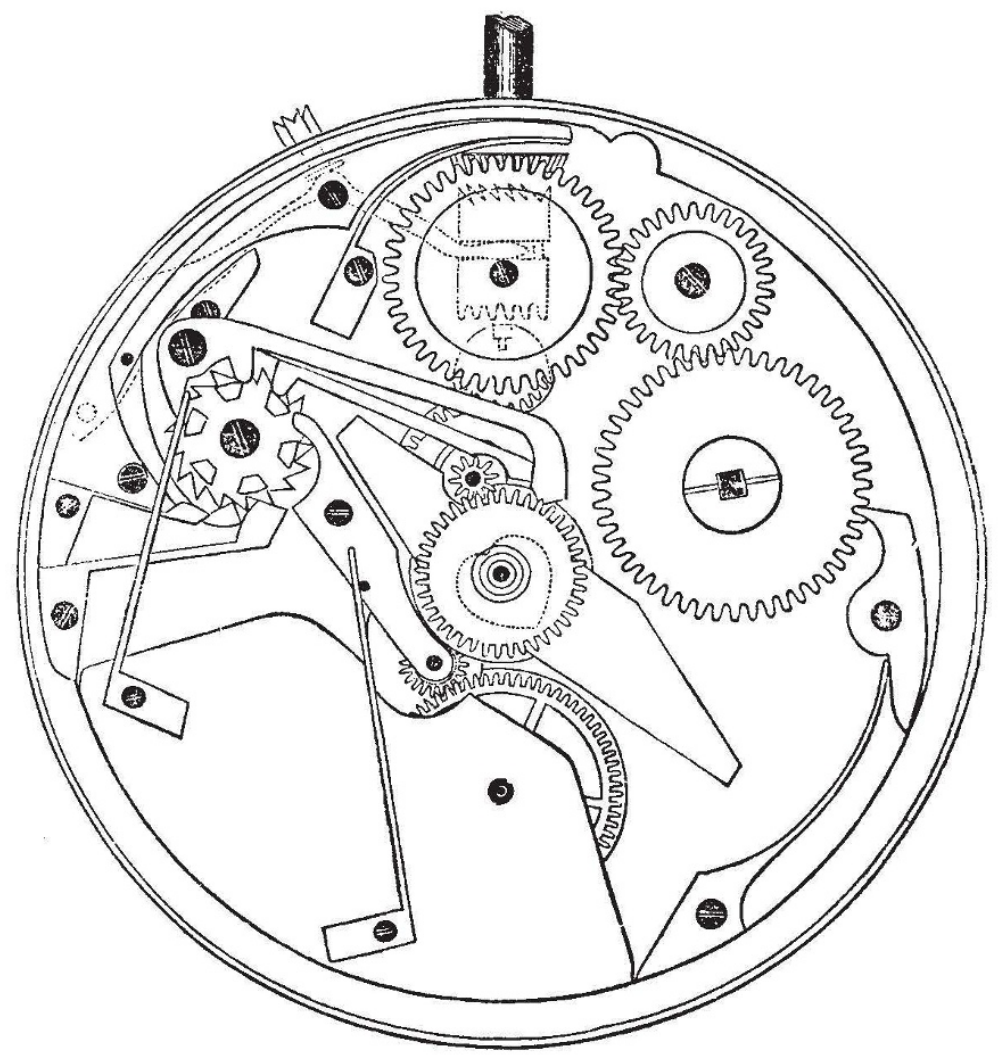

FrG. 5.-Chronograph with Swiss Keyless w rrk.

About twenty-five years elapsed before any satisfactory method was established of causing the keyless mechanism to set the hands of the watch in addition to winding it. The method which was first adopted had the drawback that the hands could not be put backward when the watch was fully wound. At present two systems are principally employed, they are known as the English and Swiss. Fig. 4 shows the English or rocking-bar plan. Wheel $b$ is in connexion with the crown-piece, and communicates with the square of the shaft passing through the barrel by means of the wheels $i$ and $g$. Wheels $i$ and $h$ are on a lever, or rocking-bar, pivoted about the

We are indebted to Mr. David Glasgow, Vice-President of the British Horological Institute, and the Messrs. Cassell for the use of Figs. 2, 3, and 4, and to Mr. F. J. Britten, Secretary of the British Horologica: Institute, for the use of Figs. 5,6 , and 7 . centre of $b . \quad p$ is a push piece acting against $c$, which is a part of the rocking-bar. When $\not p$ is depressed by the finger or thumb, it lifts $i$ and forces down $h$ into connexion with $l$, which communicates with the pinion of the minute-hand $e$. If the crown-piece now be turned, the hands will follow; no winding is performed, because $i$ has been lifted away from $g$. When the pressure is removed from $p$, a spring, $s$, puts the rocking-bar back again into its normal position, $i$ engaging $g$, and $h$ quitting $l$. The Swiss system is different in this : that connexion with the winding or set-hands wheels is made by a pinion faced with teeth on both sides, sliding up and down the stalk of the crown-piece. The normal position (as in the English system) is engagement with the winding-wheels, but when the push piece is depressed the pinion moves away from its engagement with the winding-wheels, and 
takes up with the set-hands wheels. In Fig. 5, which we shall refer to again further on, this arrangement can be readily perceived.

To understand repeating work-in which a good deal of progress has been made-it will be as well at first to refer to Fig. 6, which shows the mechanism of a clock chiming the quarters. On the left will be seen an anchorshaped piece with teeth in it, called a "rack." At the foot of the rack will be seen a star wheel carrying a piece in form similar to a snail. This piece is called the "snail," and it has twelve gradations corresponding to the twelve hours. On the right will be seen another rack and snail which do duty for the four quarters. Both the quarter and hour racks are at present held free of their respective snails by the hooks shown in the diagram. The method of action is as follows :- At each hour the quarter rack, by means of mechanism connected with the going train of the clock, gets itself liberated from the hook and falls upon its snail. The distance through which it falls is determined by the depth of the depression in the

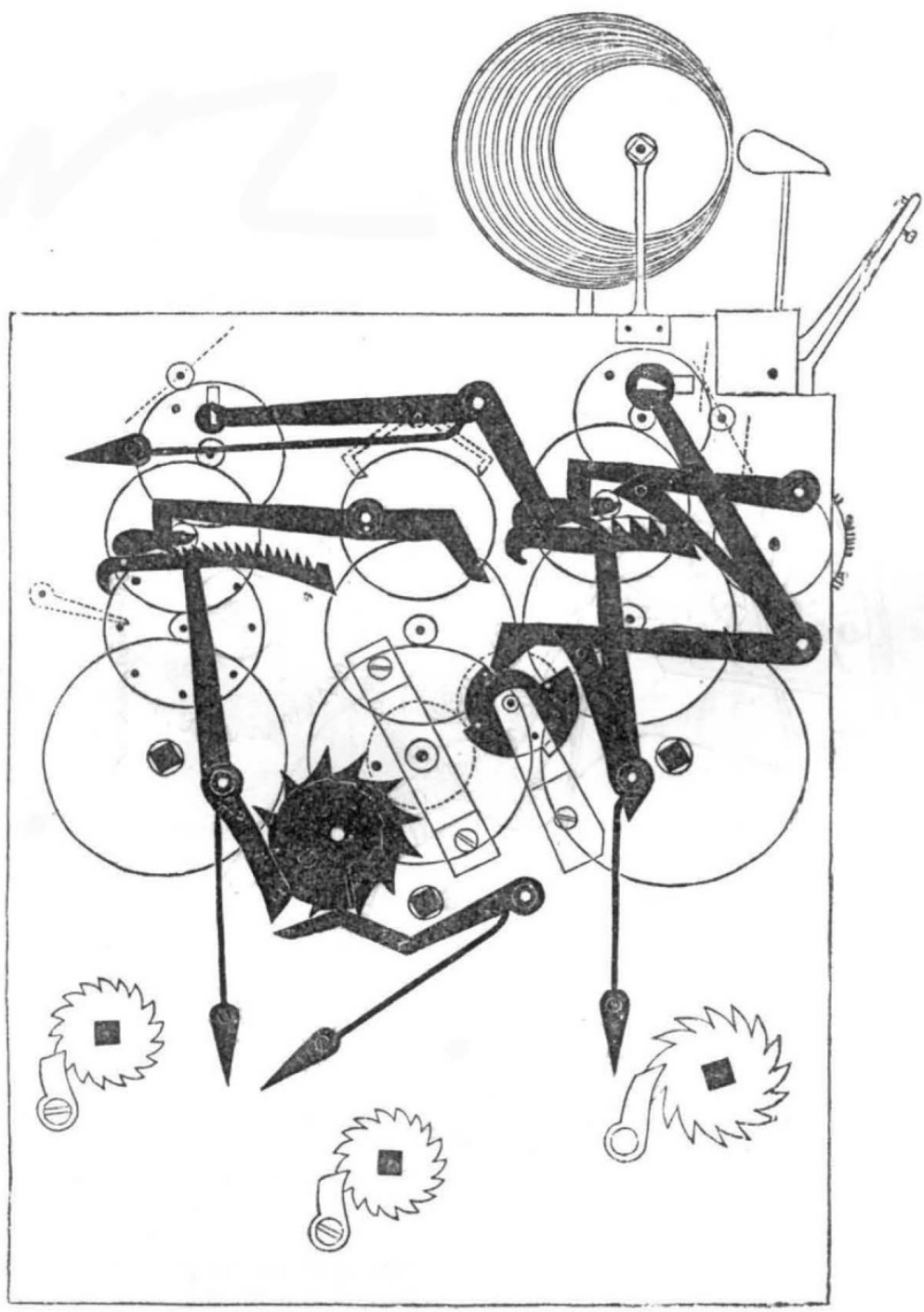

FIG. 6.-Hour anJ Quarter striking mechanism.

snail which is opposite to it. The quarter train having also got freed at the same time, proceeds to run, and winds up the rack again in doing so. The distance through which the rack has fallen determines the length of time the quarter train runs, and consequently the length of the chime. In falling the quarter rack also discharges the hour rack. The hour train is held until the quarters are finished; at their conclusion the hour rack is wound up by the hour train through the distance it has fallen (which depends upon the depth of depression in its snail opposite to it), and the number of the hour struck is in proportion.

The light which the foregoing throws upon repeating work is with regard to the snail and rack arrangement. When you move the slide of a repeating watch you do two things. You wind up the main-spring, which actuates the repeating train, and the extent to which you are able to do so depends upon the depth of the depression in the snail which is opposite to the piece which you are moving. When you reach the bottom and press against 
the snail, it is so arranged that the snail shall give a little. The small play the snail has, the distance it can move under pressure, is sufficient to discharge the quarter rack on to its snail. In repeating work the quarter rack is also an "all or nothing piece," for this reason, that until it is discharged the hammer which strikes the hours is hung up, and should you not press down the slide sufficiently to reach the bottom of the depression in the

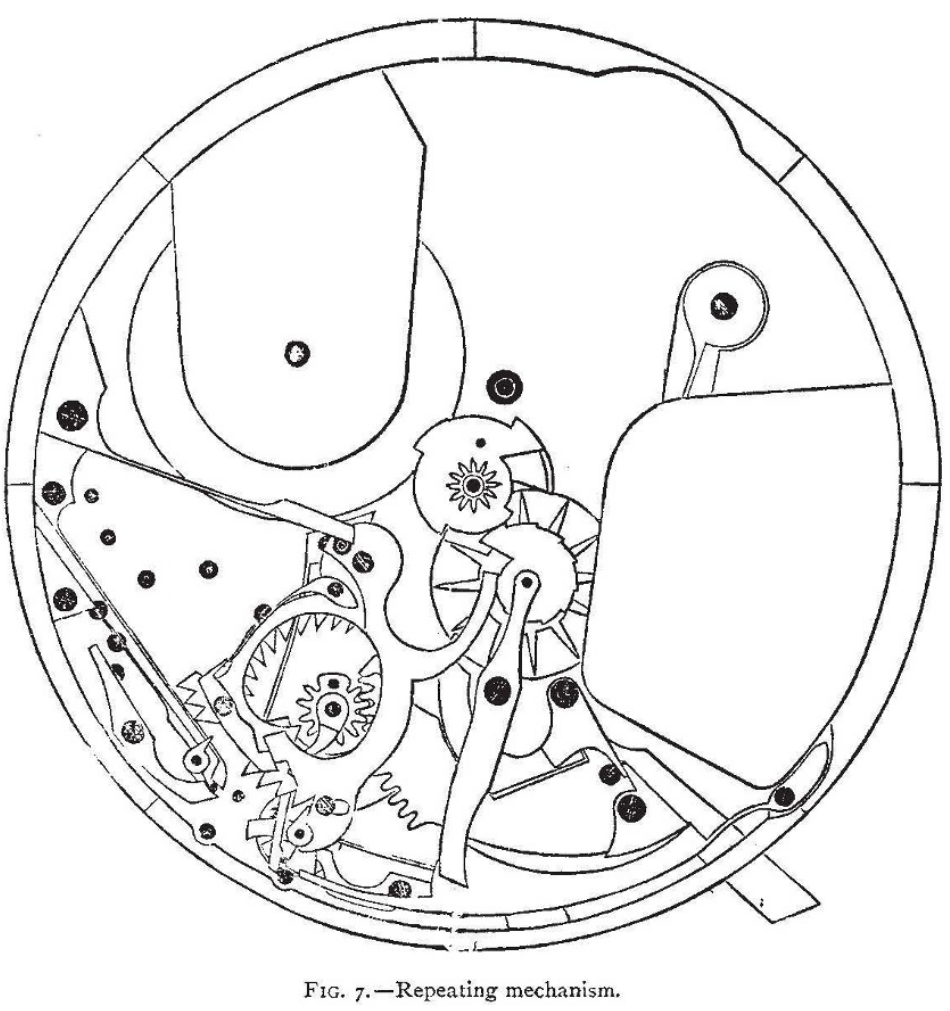

snail no blows are struck, so it is not possible for the repeating work to give you a false answer. Fig. 7 illustrates repeating action. Clock-watches are watches which strike the hours and quarters spontaneously; their action is exceedingly complicated, and, unless their mechanism is seen, is almost incapable of explanation. ( $T o$ be continued.)

\section{THE RECENT DROUGHT.}

THE spell of dry weather recently experienced over the United Kingdom has been so unusually prolonged, and its effects have in many instances been so disastrous, that a brief inquiry into its history and general results may not be without interest. In the present article it is therefore proposed to take into consideration, -firstly, the conditions of barometrical pressure under which the drought occurred; and secondly, the actual deficiency of rainfall experienced in various parts of the country.

With respect to the first point it will readily be surmised by those who are in any way acquainted with the subject of our meteorological changes that the general distribution of pressure during the recent dry spell was anticyclonic. At times, and notably during the second half of June, the middle of July, and the early part of August, the anticyclonic conditions ruled supreme over the entire Kingdom. On other occasions, however, the influence of the high pressure areas was confined to a portion of our islands, the favoured localities being usually those included within the eastern or the southern half of Great Britain. With these latter conditions the extreme western and northern districts were influence t to a very partial extent by the anticyclone, and to a much greater extent by areas of low pressure, the centres of which were, however, in nearly all cases at a considerable distance from our shores. On a few rare occasions the main disturbances were accompanied by shallow subsidiary depressions, which advanced directly over us, and occasioned the temporary bursts of showery weather which occurred from time to time. The most important and general instances of this kind were observed during the second week of July and towards the end of the same month; but in the former case there were isolated portions of our southern and south-eastern counties which remained altogether unaffected by the disturbed weather, while in the latter instance the showers were in many districts far too insignificant to be of any real value.

Although an endeavour has thus been made briefly to account for the unusual drought which occurred, one cannot but feel that beyond and irrespective of the various pressure movements which were reported from time to time there was a distinct tendency for the weather to remain dry and warm. Instances were not wanting of the prevalence of very disturbed conditions of pressure without any corresponding break up in the atmospherical appearance. Of this, two recent examples may be cited. On the afternoon and evening of August 12, a depression formed 